\title{
"SPRAY TECHNIQUE: TRACING THE SKETCH TRADITIONS OF LIMESTONE CAVE IN LENGGONG, PERAK"
}

\author{
Fatan HamamahYahaya, Sakinah Abu Bakar, Norziani Dahalan @ Omar and Nazirah MdYusof \\ School of Distance Learning Education \\ Universiti Sains Malaysia \\ 11800, Minden, Penang, Malaysia
}

\begin{abstract}
Archaeological research provides the widest opportunity for researchers to analyse various aspects and disciplines appropriate to the subject and the object of choice. Subject and object selection is the work of exploration artefacts found in particular sites and archaeological heritage. Exploration and excavation on of a world heritage site such as Lenggong enables researchers to uncover various archaeological artefacts that are rich and meaningful. To find evidence of the strength and benefits of an artefact, further studies on each artefact should be carried out continuously. This essay will track the wisdom of the ancient artists use to produce paintings in a limestone cave in Lenggong, Perak, using spray techniques. Some artefacts that are identified as cave paintings show a very interesting sketch technique that are unique and special. This essay will also examine some of the cave paintings in other caves in Perak and also other caves in several countries as comparison. Studies involving cave paintings in Malaysia are new compared to Western countries. Thus, the study of one of the technique which is spray technique can open the eyes of the audience to acknowledge and recognise the ancient heritage. It also hoped that this study is able to increase the body of knowledge that goes beyond the boundaries of the arts district and the country.
\end{abstract}

\section{INTRODUCTION}

Archaeological research is a very broad area of research coverage. Artefacts and archaeological findings present a civilization that tells about the culture and life of a nation and humanity. The researchers have the opportunity to learn and apply various aspects and disciplines related to the field of archaeology. This is because the work of the archaeological excavation site revealed various cultural artefacts that are invaluable and meaningful to the development of humanity. This phenomenon is no exception forWorld Heritage site like Lenggong ${ }^{1}$, Perak, Malaysia.

To find evidence of the strengths and benefits of an artefact, further study of each artefact should be carried out continuously. Among the archaeological findings in Lenggong Heritage Site are paintings made by ancient artists that can be found on the walls of several limestone caves in Lenggong, Perak. Among the paintings are in Badak Cave and Dayak Cave. Early observations found these paintings are produced with a very interesting variety of techniques. This essay will try to trace the technique which is spray technique used by ancient artists to sketch sketching and painting on the walls of the caves.

\footnotetext{
1Lenggong has been declared to be a world heritage site in 2014 after 25 years after a group of USM researcher shown the uniqueness of this particular valley in prehistoric times. Recognition by UNESCO shows the uniqueness and specialty prehistoric Lenggong Valley should be shared with the world community. One of the privilege of Lenggong is the place are known as Palaeolithic stone tool making workshop and the discovery of 72 sites in the limestone caves Lenggong Valley. In addition, special findings, especially prehistoric human skeletons of Perak Man. Perak man is a Palaeolithic human skeleton buried in the GunungRuntuh Cave about 10,000 years ago is the most complete prehistoric skeleton in the region to represent that age.
} 
Some artefacts that are identified as cave paintings show a very interesting sketch technique that is unique and special. This essay will also make comparison with some of the paintings on the walls of some caves in Perak such as in Tambun Cave and Kelilawar Cave. The same scrutiny for a number of sketches on the walls of some caves in several archaeological sites around the world will also be highlighted as a comparison.

Studies involving cave paintings in Malaysia are new compared to Western countries. Thus, the study of one of the techniques known as spray can open the eyes of the audience to recognize this ancient heritage closer besides exploring the development of the visual arts of ancient times. This study will add to number of research to the arts in general and artistic heritage of knowledge of the world beyond regional and national borders.

One of Malaysia's cave treasures is Tambun Cave paintings that are located approximately 300 meters from the town of Tambun, Ipoh, Perak with a variety of cave paintings. Ancient paintings found on the wall of the caves is essentially narrative.

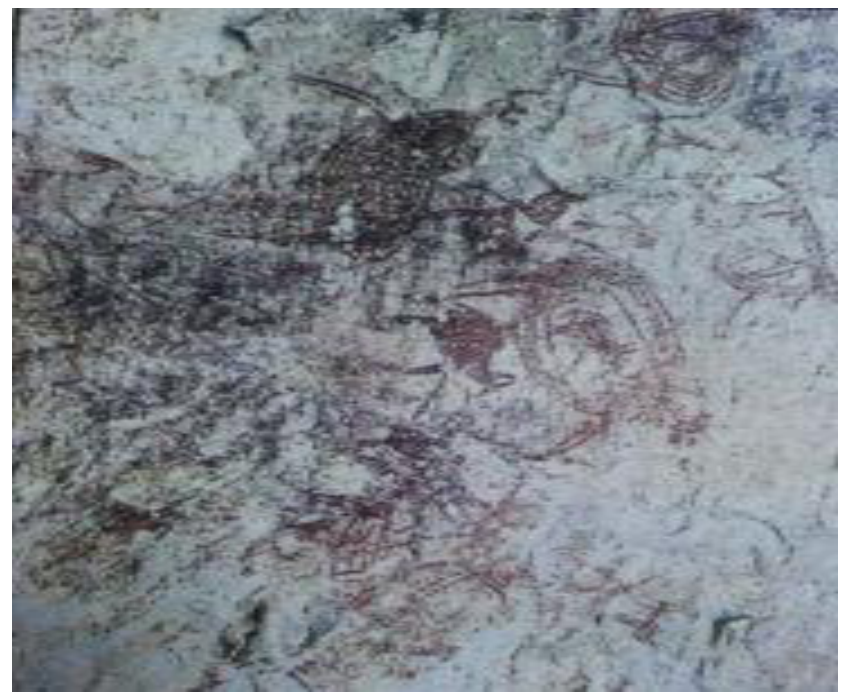

Plate 1

Drawing found in Tambun Cave, Perak

There are also a number of cave paintings found in Badak Cave and Dayak Cave, in Lenggong, many cave paintings depicted the image as displayed in the drawing below: 


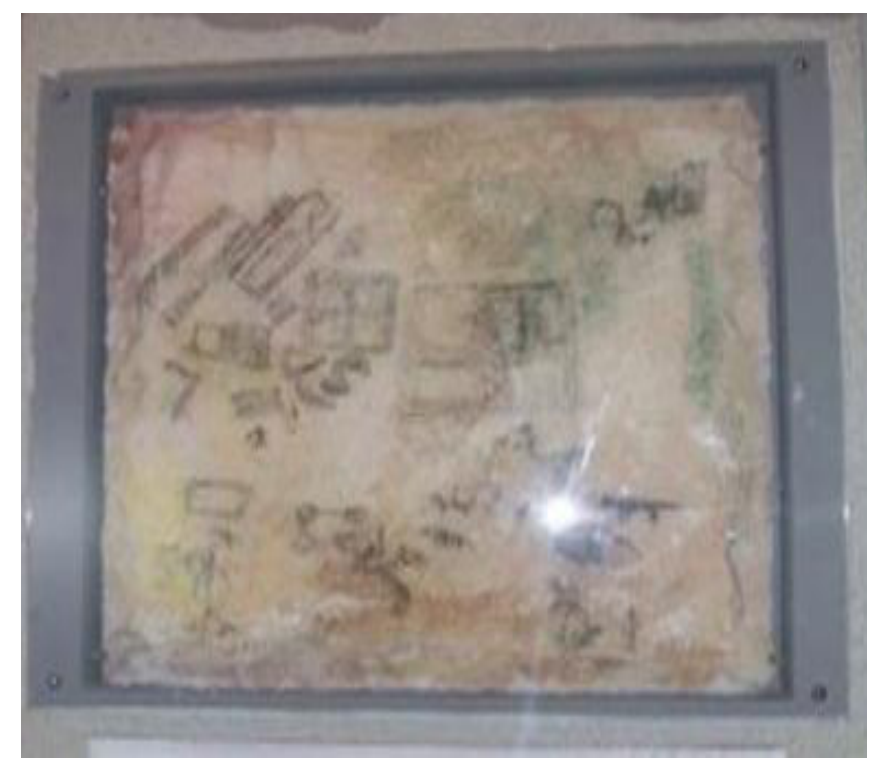

Plate 2

Cave painting found in Badak Cave, Lenggong, Perak

The sketching shapes has been identifies as human figures in multiple positions. There are also animals shape and fauna like monitor lizards $\&$ dogs (ridden by human). Other shapes is oval that look like coffin with lying-down human figure sketching and other shapes similar to daily-use tools that are hard to be match with the tools used nowadays.

The earliest cave wall paintings is believed to be produced by using manganese or haematite found in Tambun Cave, Perak and Kain Hitam Cave, Niah, Sarawak. Paintings in Tambun spotted the drawings of animals such as deer and dugongs, as well as geometric drawings and prints effect of hand. In Kain Hitam Cave, Sarawak, comprising paintings drawn boat as a symbol associated with burial practices included in the body of the boat is placed on the floor of the cave. The paintings are considered a symbol of the spirit journey to another world. Painting in Kelawar Cave in Sungai Siput, Perak are depicting animals and geometric motifs. On the other hand, cave paintings in the Badak Cave, Lenggong, Perak, are made to express the experience and activities of indigenous peoples. Many other cave paintings in Lenggong can be explored from the perspective of the visual arts.

In western countries such as France, the ancient paintings found in the caves of Lascaux 2 are mostly described as hunting and adventure. Similar paintings are found in caves Tewet, Indonesia, West Africa's Cave, Cave of Altamira and Cave Cueva de las Monedas, in Spain. Cave painting is said to have existed since the Palaeolithic ${ }^{3}$ times. The paintings were not only associated as a decoration, but as evidence that the cave had been inhabited by humans.

\footnotetext{
${ }^{2}$ The best known cave paintings are those found in 1940 at Lascaux, in the Dordogne region of Southern France. They have been dated to about 15,000 BCE. The scenes of the walls are truly remarkable. The Lascaux painters depicted cows, bulls, horses and deer along the natural ledges of the rock, where the smooth white limestone of the ceiling and upper wall meets a rougher surface below. Lascaux has about 600 paintings and 1,500 engravings. Ibex, a bear, engraved felines, and a woolly rhinoceros have also been found. The animals appear singly, in rows, face to face, tail to tail, and even painted on top of one another. Their most characteristics features have been emphasized.

${ }^{3}$ Palaeolithic Age is the age that began about 50000 to 100000 years ago. This time around the year $50000 \mathrm{BC}-10000$ $\mathrm{SM}$. At this time, Peking man and Java man haveexisted. In Africa, Europe and Asia, Neanderthal man was living in the early $50000 \mathrm{BC}$, while the year $20000 \mathrm{BC}$, Cro- Magnon man, man is master of modern culture in North Africa and Europe. In this day and age, people lived a nomadic or semi-nomadic in small groups to find food. They hunt animals, catch fish and collect forest products for food. They do not know the cultivator. They used stone, wood and animal bones to make hunting
} 


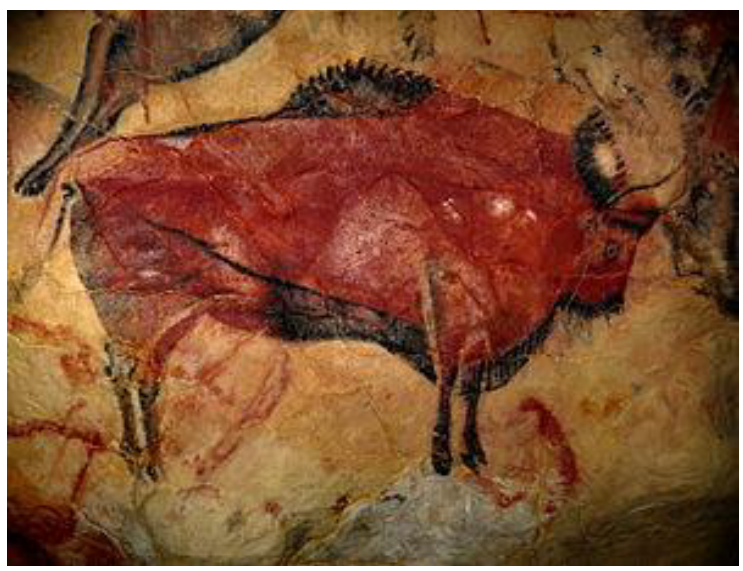

Plate 3

Altamira Bison's drawing that found in Altamira Cave in Spain

This painting shows the skills of the painter on using the elements of line, space and color to display clear images even on the cave wall surface that is not flat. What is the basic ingredient of natural fertility used to be able to produce red, black and brown although the painting had been thousands of years of age?

Some theories also explain that the cave paintings used for communication between them, while another theory assumes cave paintings are religious symbols or rituals performed by the society at the time. The probability of selection is selected caves are associated with religious rituals mysterious nature, apart from a group of people at that time to be alone. Religious symbols found on cave paintings of great importance to the field of archaeology as this religion symbol is relevant to it because of its emphasis on ritual and its de-emphasis of the overall cosmology. Most rituals, after all, are closely related to material culture, and, as such, are often represented in the archaeological record. The analysis of past culture behaviour is thus archaeology's major contribution to the study of religion.

Caves often are hidden and special and therefore make it suitable for such ceremonies. Images are frequently found in cave paintings are large wild animals, such as bison, horses, aurochs, and deer, as well as drawings of human hands as well as abstract patterns. These large animal motifs carved using bone or ivory. Cave paintings rarely painted the human form because usually people are more schematic with detailed drawing and not naturalistic compared to the paintings of animals.

Drawing is believed to have started much earlier than writing tradition. Drawings were found since the Stone Age. The discovery of paintings in the caves walls are believed to be produced by ancient man. The painting depicts the everyday life activities such as religious rituals, hunting and adventure. Among the earliest cave paintings found in caves in Malaysia are in Tambun, Perak, Niah Cave in Sarawak and Balambangan Cave in Sabah. Most of these paintings feature images of flora and fauna with interesting and unique techniques. Paintings can be examined and understood through modern visual arts barometer evaluation that emphasizes the structural elements, line, space, color and theme. However, every painting displays its own niche based on the methods or techniques used; part

equipment. These devices are also used to hack and defend themselves from the enemy. They made clothing from animal skins. Apart from that they have also learned how to use fire to cook, keep warm and scary animals. They know how to use fire as a forest fire watch.

This man lived in caves or huts made of sticks and grass. Cave or hut is essential in order to protect themselves from wild animals or bad weather. They practice animism that everything has a soul. On cave walls there are pictures drawn by them to express their ideas and feelings. 
of it to apply more than one technique. This assumption should be proved by continuous research to identify the aspects of art that can be matched and linked with the question of date and important issues in the field of archaeology. Cave paintings also depict an image or drawing hand print. The clarity of the image depends on the cave wall quality; if the wall is soft surface, it will make it easier to hand print that were with one hand. Hand prints are not usually neutral while the writing that is not understood (Gargas and Cosquer, 1996). Images and drawings are believed to mark the hand by applying the technique of its own.

Watchel (2010) believed that ancient artist use the technique of blowing by chewing a piece of charcoal to dilute it with saliva and water. Then he blows out the mixture on the surface of a wall, using his hand as a stencil. The drawing demonstrates how cave archaeologist Michel Lorblanchet and his assistant used the step by step process of the original markers of a cave painting at Pech-Merle in France created a complex design of spotted horses. Lorblancet then turn himself into human spray that can produce clear lines on the rough stone surface are much easier than he could with a brush. To create the line of a horse's back, with its clean upper edge and blurry lower one, he blows pigment below his hand. To capture its angular rump, he places his hand vertically against the wall, holding it slightly curved. To produce the sharpest lines, such as those of the upper hind leg and tall, he places his hands side by side and blows between them.

Among the techniques that can be identified is the technique of colouring directly on the image drawn on the surface of the stone, whether to start with a line or directly with colour ; some are painted with rough and thin lines using tools such as charcoal and so on. Colours are often used in cave paintings which consist of red and yellow colours, hematite, green and charcoal. There is also a hint in the form of cave paintings of animals drawn on rock surface and connected to several other stone surfaces such as drawing a dugong found in Tambun Cave, Perak, Malaysia. The evidence is clear that the paintings are not just limited to a small canvas.

Particular interest is a painting that depicts images of flora or fauna and hand prints in the form of a realistic, beautiful and smart. The images are believed to be made using spray technique. The device used is still a mystery. If painting can be associated with the early settlement of indigenous people (in Lenggong case) then the closest activity is blowgun (usually to catch animal). Could they have created a special tool for the realization of their art work so the effect of the tools similar to the use of spray technique?

\section{SPRAY TECHNIQUE: EXAMPLES OF PAINTINGS}

In the context of modern art, spray painting techniques means a technique that uses a type of tool to spray out the paint, ink or varnish. Francis Davis Millet in general has been exploring painting that uses using spray techniques. Millet is the mixed of oil and white paint that can be applied through the medium of special hose and nozzle that can save time compared to traditional technique. As a result, Edward Seymour has created a spray paint that can be applied directly from aerosol cans.

If the ancient artists are believed to use spray technique to produce cave paintings, then maybe they are using different tools compare to the tools use in the present era. In term of colors, history has clarified that natural materials have been used as the color to illustrate the cave paintings. The following are examples of images that are believed to employ spray technique in the drawings. 


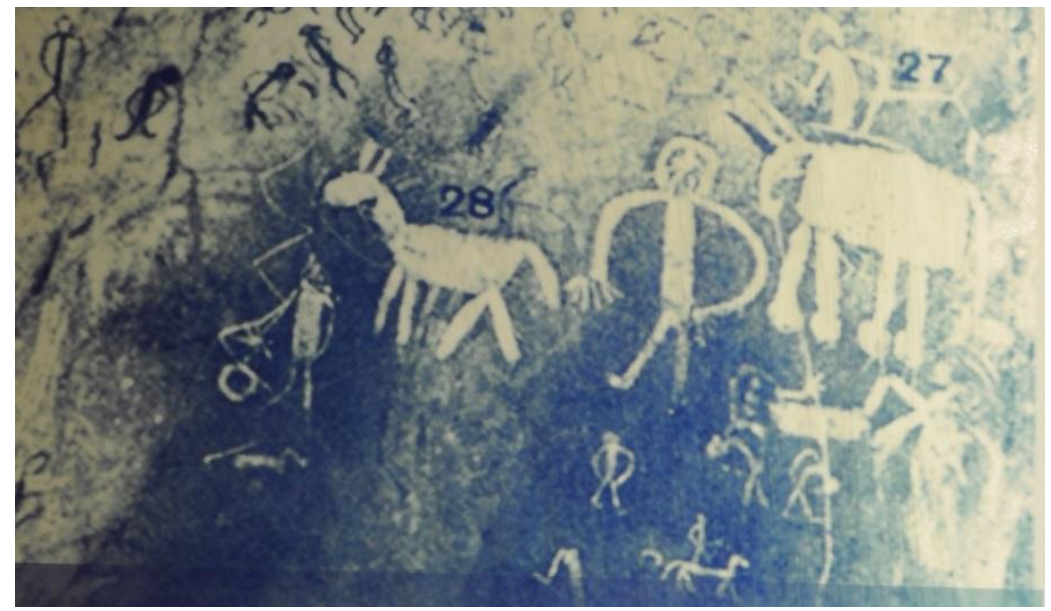

Plate 4

Spray technique in Badak Cave, Lenggong, Perak

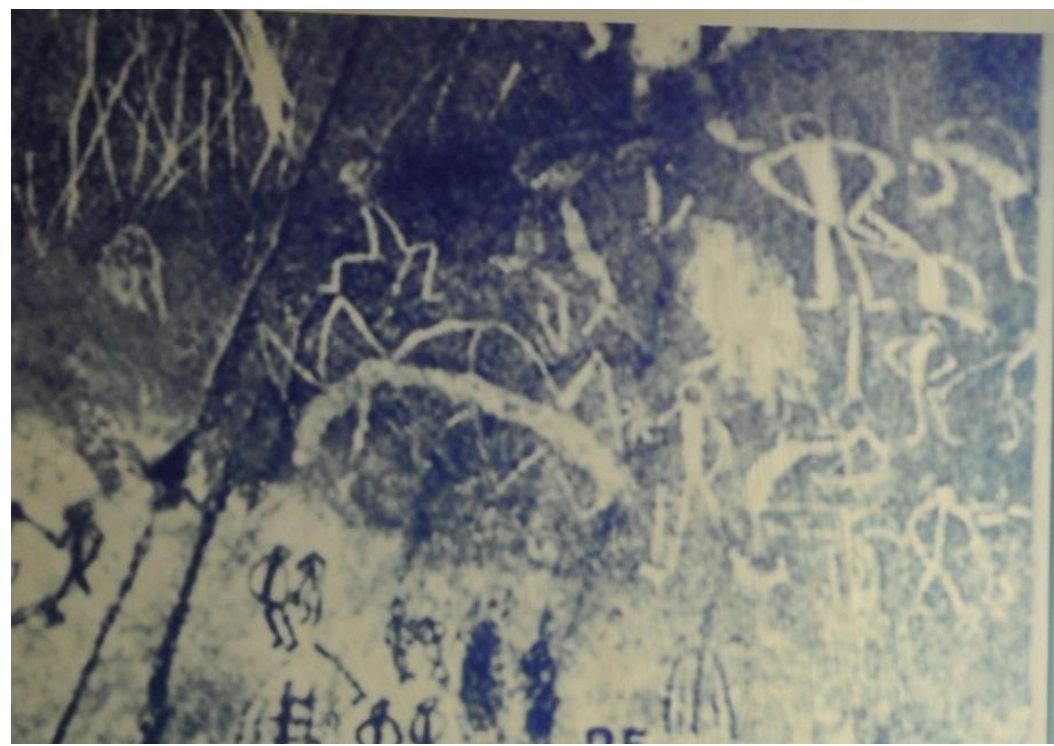

\section{Plate 5}

Spray technique in Badak Cave, Lenggong, Perak

The two plates (4 \& 5) appear on the two small parts of a fairly large painting. Only images that stand out on the surface ' canvas ' are made as the focus to show the clear image that are formed by spray technique. Note the three main images in plate 4 that shows the images of an elephant, a horse and a human. The images are as clear in shape as a standout from the dark color background. These images may be drawn in advance on other materials (patterns) such as skin before it was placed onto the surface of the cave walls after being sprayed with colour before opening the image pattern. The same technique is used to produce the images smaller. There are also images that are formed directly by drawing immediately onto the surface of the cave wall without patterns using tool such as charcoal which acts as a pencil. Whatever the tool, make sure it is capable of lyrical and subtle lines for drawing.

The same technique is believed to be used in hand print found in Tewet cave of Borneo and Cueva de las Manos in Spain. There is an assumption to say that this is the real fingerprints that are mounted on the walls of the cave before being sprayed with color around it. 


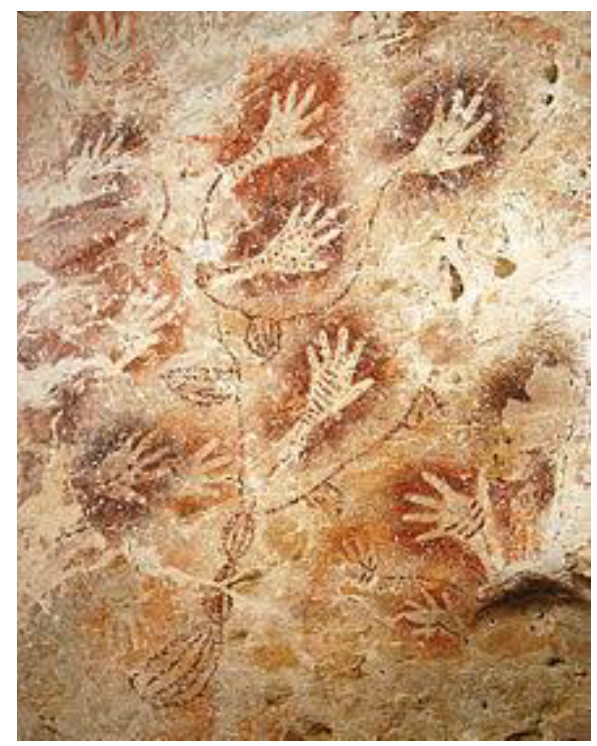

\section{Plate 6}

Hand prints in Tewet Cave, Borneo, Indonesia

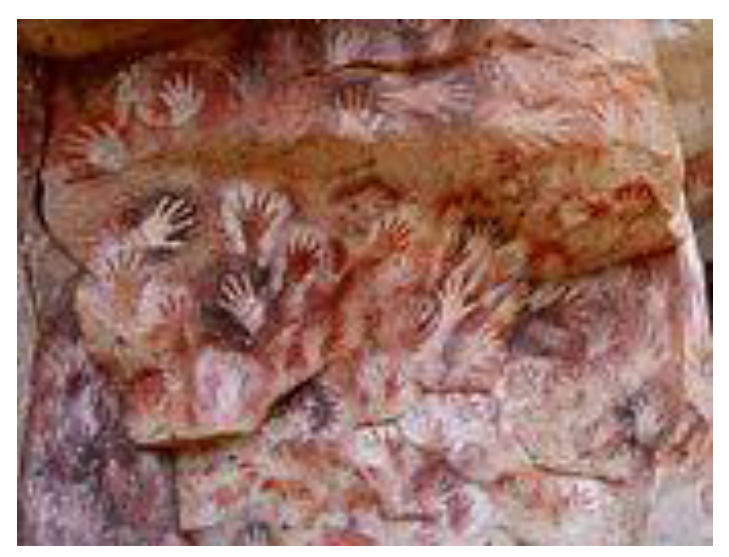

Plate 7

Hand prints in Cueva de las Manos in Spain

Drawing hand stamps are abundant in Indonesia and are believed to use a spray technique. This marks the discovery of hand with red painted background which belongs to a woman left hand because of the small size. Drawing hand stamp is believed to be made by stretching the fingers on caves wall and then sprinkled red paint on it. The question is what is the tool used to spread the colour until the image looks very like hands and form a line? Findings hand print was discovered by C.H.M. Heeren - Chazine in 1950 in Leang PattaE4, Sulawesi, Indonesia.

${ }^{4}$ Heekeren Research in Cave Birds, Sulawesi also found hand painting marks. Cap is made from hand-left hand mark. Other findings made by C.J.H. Franssen is on hand print in cave paintings near Sarippa, who later called JariE cave. Based on the findings Heekeren and Franssen has done research in the cave and found a total of 29 hand print, which consists of four groups; composed of 7 and 5 hand print with red background print, there are four marks of the hand; one of which has four fingers and the other had only three fingers. In addition, there are also drawings that do not literally hand print fingers. 


\section{SUMMARY}

Analysis of the sketches found in several caves in Lenggong and other caves in Malaysia and as well as other caves in the world in this essay is a preliminary study. Cave paintings are believed to have used multiple techniques and it should be given special scrutiny by future generations. The efforts made by certain parties in the preservation and conservation of these drawings deserve appreciation and support in the form of scientific research. Ancient heritage such as cave paintings in Lenggong are believed able to open a new chapter in Malaysia, especially in the field of heritage tourism as other countries in the world have translated into a useful form of knowledge and keep it as a protected heritage.

\section{REFERENCES}

Cave paintings of the world. In brief history of cave paintings. Retrieved from www.beaconlearningcenter.com

Chazine, J-M. (2005). "Rock Art, Burials, and Habitations: Caves in East Kalimantan". Asian Perspectives 44 (1): 219-230. doi:10.1353/asi.2005.0006. Retrieved 12 February 2014.

Saidin, M (2013) Arkeologi Lenggong: Keunikan dan keistimewaanya in Lenggong daripada pelbagai perspektif (ed) Abu Bakar., S. Kuala Lumpur: Dewan Bahasa \&Pustaka.

UNESCO World Heritage Center.Retrieved 27 February 2014.

Thomas. D.H. (1989). Chronology building: Low-level archaeological Theory in action. In. Thomas. D.H. Archaeology Third Edition.Pg. 229.Amerika Syarikat. Harcourt Brace and Company.

Thomas. D.H. 1989. Middle-Range Research: Ethno archaeology and Experimental Archaeology. In. Thomas. D. H. Archaeology Third Edition.Pg. 262.Amerika Syarikat. Harcourt Brace and Company.

Watchel.E (2010). The First Picture Show: Cinematic Aspects of Cave Art. Accessed from http://www.jstor.org/stable /1575898 on 02/05/2011. Leonardo, Vol. 26, No. 2 (1993), pp. 135140

Whitley, David S. (2009). Cave Paintings and the Human Spirit: The Origin of Creativity and Belief. Prometheus.p. 35.ISBN 978-1-59102-636-5.

Zorich, Zach (March/April 2011). "A Chauvet Primer".Archaeology64 (2): 39.

\section{Acknowledgement}

The authors would like to thank Universiti Sains Malaysia for the Sustainable Tourism Cluster University Research Grant (Grant No. 1001/PTS/8660012) that helped made this study and paper possible. 